\title{
Invasive Procedures in Monochorionic Twins
}

\author{
${ }^{1}$ Aris Antsaklis, ${ }^{2}$ Panos Antsaklis
}

\begin{abstract}
Monochorionic twin pregnancies (MC) are less frequent but they are considered higher risk pregnancies compared to dichorionic pregnancies. As a result, determining the chorionicity of a twin pregnancy is of vital importance for the surveillance and management of the pregnancy. The problem originates from the fact that monochorionic twins have one placenta, and as a result the circulation of the two fetuses is closely related to each other mainly through anastomosis of the placenta. The number and type of anastomosis is of great importance for the course of the pregnancy. Diagnosis of chromosomal abnormalities in such pregnancies requires excellent knowledge of invasive procedures and good clinical skills. Monochorionic twins are at increased risk for unique complications including twin-to-twin transfusion syndrome (TTTS), selective intrauterine growth restriction (sIUGR), and twin-reversed arterial perfusion (TRAP) sequence. Twin-to-twin transfusion syndrome is a very well known and described complication of monochorionic twin pregnancies and must be considered and checked in each monochorionic pregnancy. Selective feticide is not a method used very commonly in MC pregnancies, but may be applied in selected cases. For TTTS laser treatment of the anastomosis is a method of choice, but should be performed in centers with experience.
\end{abstract}

Keywords: Invasive procedures, Monochorionic twins, Twin-to-twin transfusion syndrome.

How to cite this article: Antsaklis $A$, Antsaklis $P$. Invasive Procedures in Monochorionic Twins. Donald School J Ultrasound Obstet Gynecol 2015;9(3):280-292.

Source of support: Nil

Conflict of interest: None

\section{INTRODUCTION}

The prevalence of multiple pregnancies varies worldwide, ranging from 6,7:1000 deliveries in some countries (e.g. Japan) up to 40:1000 in some other (e.g. Nigeria). ${ }^{1}$ The respective prevalence in Europe and North America is around 11:1000. Infertility treatment and the advances

\footnotetext{
${ }^{1}$ Professor, ${ }^{2}$ Teaching Assistant

${ }^{1}$ Department of Obstetrics and Gynecology, University of Athens, Athens, Greece

${ }^{2}$ First Department of Obstetrics and Gynecology, Department of Fetal Maternal Medicine, Alexandra Maternity Hospital University of Athens, Athens, Greece

Corresponding Author: Panos Antsaklis, Teaching Assistant 1st Department of Obstetrics and Gynecology, Department of Fetal Maternal Medicine, Alexandra Maternity Hospital, University of Athens, Athens, Greece, Phone: +32107771386, e-mail: panosant@gmail.com
}

in assisted reproductive technique is associated with an increase in multiple pregnancy, and as a result with an increase of monochorionic twins. The incidence of monochorionic (MC) twins is about 1 to $3: 1,000$ pregnancies, and account for almost $20 \%$ of all twin pregnancies. ${ }^{2}$ Monozygotic (MZ) twins arise from one oocyte and one sperm cell, which finally produce two fetuses rather than one. Depending on the day of the division, if the division occurs between the 4th to 12th day after fertilization, the fetuses that derive from that division, are in different amniotic sacs, but they share the same placenta and are called monochorionic. ${ }^{3,4}$ So, all MC twins by definition are considered to be monozygotic (MZ), that is, they have the same chromosomes and though they may have phenotypic differences and mild variations in their genotypes, due mainly to epigenetic or environmental in utero factors, their karyotypes are considered to be identical. The risk of chromosomal abnormalities is the same as for singleton pregnancies and in the vast majority both fetuses in MC pregnancies are equally affected. ${ }^{5}$ However, there have been described cases of MC twins with differences in their karyotypes and this phenomenon is called heterokaryotypic monochorionic twin pregnancy. Generally, this phenomenon is caused by postzygotic mitotic events (non-dysjunction or anaphase lag) but several mechanisms may be involved. 6,7 The theories for explaining the major or minor differences of the karyotypes of $\mathrm{MZ}$ twins involve first a mitotic error resulting in mosaicism that could occur before the separation of the two fetuses, so that, the distribution of the cell lines in the two fetuses are different. According to the second theory, the zygote may initially be karyotypicaly normal but after the separation of the two fetuses an error occurs in one of the two fetuses, causing a chromosomal abnormality. Another possibility is that of blood mosaicism due to transfer of blood cells from one twin to another, through placental anastomosis and that is the reason why for karyotyping of monochorionic twins amniocentesis is preferred to cord blood sampling. Monozygotic twins with concordant chromosomal aberration and discordant phenotypes have also been described. ${ }^{8-10}$ Mosaicism with different proportions of abnormal cells could affect each embryo differently, while variations in the proportion of placental vessels and hence, blood flow could lead to differences in the fetal growth. Finally, placental vascular anastomoses can lead 
to twin-twin transfusion, and thereby to blood chimerism and confined placental mosaicism, and differences in epigenetic control. Discordances in monozygotic twins have been described mainly for trisomy 21, trisomy 13 , sex chromosomes and other less frequent abnormalities. If one of fetuses has a non-viable abnormality, there will be early fetal demise and possibly will never be detected. If the aneuploidy is a viable condition this may give rise to a heterokaryotypic monochorionic pregnancy. ${ }^{8-14}$ So, when performing invasive diagnostic testing for karyotyping of monochorionic twin gestations, both fetuses should be sampled. Because although monochorionic twins theoretically should have identical karyotypes, rarely heterokaryotyping and discordance for chromosomal abnormalities between the two embryos may occur and sampling both fetuses is generally recommended if the patient is undergoing a diagnostic testing for fetal aneuploidy. $8,15,16$ Special attention should be paid to monochorionic diamniotic pregnancies that derive after assisted reproductive technology (ART), irrespectively of whether it is an in vitro fertilization (IVF) technique or intrauterine insemination (IUI) since the risk of difference of the karyotype in the two embryos is reported increased compared to MCDA cases that are conceived naturally. ${ }^{17-19}$ Evidence regarding the loss rates after prenatal diagnostic invasive testing in monochorionic twins is scares, and as expected due to the limited number of MCDA pregnancies no big randomized studies evaluating these data exist. Two significant studies from Canada and USA showed conflicting evidence. Millaire et al studied 45 monochorionic twin pregnancies who underwent amniocentesis for different reasons and found no fetal loses in these cases. ${ }^{20}$ Cahill et al reported an almost 6 times higher loss rate for the monochorionic twins that underwent amniocentesis (26 cases) compared to monochorionic pregnancies that did not have an amniocentesis (295 cases). ${ }^{21}$ However, the sample of monochorionic twins that underwent amniocentesis and was included in the study was limited. ${ }^{15}$

The incidence of structural abnormalities in twins is higher compared to singleton pregnancies. However, the frequency of malformations in monozygotic twins is considered to be higher than that of singleton pregnancies or even dizygotic twins. This fact has been attributed to vascular events or variations in the division of the zygote that are responsible for the formation of monochorionic twins. $^{2,22,23}$ The percentage of occurrence of the same structural abnormality in both monochorionic twins is however rare, and has been calculated to less than $20 \%$. Neural tube defects, anencephaly, holoprosencephaly, sirenomyelia and VACTERL anomalies are more common in monochorionic twins. ${ }^{1,24}$ This increased risk of fetal abnormality in twins may be subjective, as by definition twins are monitored and scanned more frequently during pregnancy, increase the percentage of diagnosis of structural abnormalities. What is more mainly due to ART twins are seen more often in women of advanced maternal age, which statistically increases the risk of fetal abnormalities.

\section{Methods of Invasive Prenatal Techniques in Twins}

Invasive procedures for fetal karyotyping in twins as expected are more challenging than in singletons. Chorionic villus sampling (CVS) and second-trimester amniocentesis for twin pregnancies both require experienced operators to ensure sampling of both fetuses and minimize procedure related risks. Fetal blood sampling (cord blood sampling) has limited application in twin pregnancies. Second trimester amniocentesis performed after 15 weeks of gestational age is considered a safe and accurate procedure for sampling all fetuses of a multiple gestation. Three techniques have been described, involving a single (one method) or double uterine entry (two methods), but they have not been extensively studied and investigated in randomized studies. ${ }^{25}$

\section{Two-puncture Technique}

The technique that is most widely accepted is the one that involves two different punctures, one for each sac, using two different needles and two different puncture sites on the uterus, preferably one on each side of the intertwin membrane and noted on ultrasound. The method was first described in the beginning of 80 s by Elias et al. ${ }^{26}$ With twin pregnancies there is a risk of puncturing unintentionally the same sac twice, and this risk for all pregnancies has been estimated to around $1.8 \%$. The use of specific dye has been tried in several studies, in order to minimize the risk of sampling the same sac, rather than both fetuses. This technique involves injecting a dye into the first sac immediately after the collection of the first amniotic fluid sample. ${ }^{27,28}$ Then, this first needle is removed and the second needle is inserted to the second amniotic sac for the collection of the other sample. If during this aspiration the presence of dye is identified then there is a possibility of the sample been wrongly collected from the first sac again, rather than the second one, and the location of the puncture site can be modified until a clear sample is obtained. ${ }^{29,30}$ The most common dyes that have been used are methylene blue and indigo carmine. Methylene blue was one of the first dyes to be used, and has been associated with small bowel atresia, fetal hemolysis and fetal death and its use has been abandoned. Indigo carmine has 
also been used, and has not been associated with an increased risk in congenital anomalies, though a mild vasoconstrictive effect following intravenous injection has been described. ${ }^{31,32}$ However, some studies found a relationship with neonatal jejunal atresia and always the injection of a foreign substance in the amniotic cavity is of some concern. Another technical disadvantage with the instillation of indigo carmine is that the dye tends to concentrate at the bottom of the amniotic sac before it diffuses to the entire amniotic cavity. ${ }^{33-36}$ Nowadays especially after the advances of ultrasound technology and the better picture that they offer most amniocentesis are without the use of dye but with direct ultrasound guidance.

\section{Single Needle Insertion Technique (Single Uterine Entry Technique)}

The second amniocentesis technique is the single needle insertion technique (single uterine entry technique) according to which the needle is inserted close to the intertwin membrane under ultrasound guidance and it was first described by Jeanty et al in the early $90 \mathrm{~s} .{ }^{37}$ A fluid sample is taken from the first sac, and then the needle is advanced with ultrasound guidance through the membrane into the second sac. The first 1 to $2 \mathrm{ml}$ of amniotic fluid is discarded to decrease the risk of contamination from the first sac, and then a sample is taken from the second sac. Advantages related to this technique involve: only one uterine puncture instead of two, shorter duration, less maternal pain and discomfort, and finally better confidence that we have sampled two different twins. However, three negative issues that are considered with this technique include (a) difficulties in entering the second sac directly-tenting dividing membrane (b) possible contamination of the sample taken from the second sac with fluid from the first fetus and (c) the risk of rupturing the intertwine membrane leading to iatrogenic monoamnionicity (pseudomonoamniotic twins) and the complications that may arise from such a condition (e.g. cord entanglement and amniotic band syndrome). ${ }^{38}$ Studies have shown a decreased risk of the above mentioned complications with the one-puncture technique, however, there are not many studies evaluating this specific technique, as it has not been applied widely, and hence the data provided are limited. ${ }^{39-43}$

\section{Double Simultaneous Visualization Technique}

Another technique that has been described is the one that involves constant direct ultrasound observation at the time of the insertion of the needle, but with simultaneous insertion of both needles (one needle into each sac) from one or different operators. This technique has been described by Bahado-Singh et al in $1992 .{ }^{44}$ However, it has not gained widespread acceptance, as it is time consuming, needs more manpower-specialized physicians involved and the positions of the amniotic sacs frequently make this technique impossible to achieve. ${ }^{1,26}$

\section{Pregnancy or Fetal Loss Rate}

The post-procedure fetal loss rate associated with amniocentesis in twins must be compared with the background loss rate associated with twins, ideally taking into consideration the chorionicity, because of the higher spontaneous loss rate in monochorionic twin pregnancies. ${ }^{45,21}$ After correcting for as many confounding factors as possible, the most recent studies report an attributable loss rate varying from 0.3 to $2.2 \%{ }^{46}$ A recent study calculated the risk of pregnancy loss before 24 weeks' gestation to be one in 64 or $1.6 \%{ }^{20}$ When a twin pregnancy follows fetal reduction of a higher order multiple pregnancy, amniocentesis does not seem to carry a greater risk of pregnancy loss than exists in higher order multiple pregnancies that undergo fetal reduction but no amniocentesis (total loss rate 8.1 vs $12.5 \%$; no statistical difference). ${ }^{47,48}$ In a review of four studies with a total of 614 twin pregnancies undergoing CVS, the overall loss rate before 22 weeks was reported at $3.1 \%$, with a total loss rate (up to delivery) of about 4.8\%. ${ }^{49-53}$ Agarwal and Alfirevic in a recent metanalysis suggested the risk of miscarriage with amniocentesis or CVS in twins increases by approximately $1 \%$, with the overall fetal-loss rates after CVS and amniocentesis being similar. ${ }^{54}$

\section{Error in Chorionic Villus Sampling in Twin Pregnancies}

The major advantage of CVS is the earlier diagnosis since it is performed in the first trimester of pregnancy, compared with amniocentesis. Early diagnosis provides in time reassurance of fetal well-being and decreases maternal anxiety. It also helps with the management of the pregnancy itself, since the diagnosis of one or both abnormal twins earlier in pregnancy offers more time for the decision of how to treat the pregnancy. What is more, if both fetuses are affected the earlier the pregnancy is terminated the less is the psychological impact on the parents.

In general first-trimester CVS in multiple pregnancies is technically more demanding than second trimester amniocentesis. A disadvantage of CVS in twins is the relatively high possibility of contamination of one sample by cells belonging to either the other twin or to the mother, leading to confusing diagnosis and needing a repeat procedure (CVS or amniocentesis). The possibility of CVS error can be accurately calculated when the 
result shows concordant sex karyotypes but the outcome of pregnancy or later ultrasound assessment shows discordant sex twins. ${ }^{26,55}$ Earlier experience reported a rate of up to $6 \%$ of CVS error in twin pregnancies undergoing CVS, whereas more recent studies report lower rates of 2 to $4 \%$, while even newer studies suggest that the contamination rate is even lower. In study that used fluorescence in situ hybridization (FISH) analysis the percentage of contamination of the CVS samples was much higher and was calculated to $11.5 \% .^{56-58}$ Jenkins and Wapner suggested taking the CVS sample near the placental cord insertion for each twin, avoiding the intertwin membrane, and using both transabdominal and transcervical approach, in order to decrease the rate of contamination. ${ }^{59}$ Current recommendation is to aim for a contamination or inadequate sampling of around 3 to $4 \%$ for each center. Weisz and Rodeck suggest that candidates of undergoing CVS for twin pregnancy should be counseled that about 2 to $3 \%$ of twin pregnancies having CVS will need re-sampling because of uncertain results. ${ }^{60}$

The risk of fetal loss in twin pregnancies is considered to be higher than in singleton pregnancies and has been calculated to around 2 to $4 \%$, although other studies have disputed this percentage showing many variations in the fetal loss rate. In one study, the risk of CVS associated fetal loss before 28 weeks of gestation did not seem to differ between twin and singleton pregnancies $(4.9 \%$ vs $4.0 \%$ ). When only chromosomal normal pregnancies are considered, the overall loss rate found in a study of 202 twin pregnancies that underwent CVS became 3.7\%, a figure that is considerably less than that of amniocentesis. In another study, the pregnancy loss rate before 20 weeks following CVS was found 3.3\% comparable to $2.8 \%$ in a control group of twin pregnancies undergone amniocentesis. ${ }^{1,61}$ Hence, it may be claimed that in experienced centers, CVS is as safe as amniocentesis for prenatal diagnosis in twin pregnancies.

\section{Fetal Blood Sampling (Cordocentesis)}

Fetal cordocentesis for prenatal genetic testing has been previously used to validate abnormal findings in amniocentesis or CVS. It has also been used in case that a rapid chromosomal diagnosis (rapid karyotyping) was pending, since the results are offered in 2 to 3 days time. Nowadays, novel molecular techniques allow accurate rapid karyotype determination, thereby limiting fetal blood sampling's application. Likewise in singletons, cordocentesis in multiples is technically challenging requiring skilled operators with extensive experience in other invasive ultrasound-guided needle procedures, such as amniocentesis and CVS. Umbilical cord is usually punctured proximal to its insertion into the placenta. A needle guide or freehand technique may be used. In a study conducted in 2003, involving 84 twin pregnancies, mainly screened for hemoglobinopathies, the overall procedure-related fetal loss (up to 2 weeks postprocedurally) was $8.2 \%$, about fourfold higher than the correspondence risk in singletons. ${ }^{62}$ However, this technique can be used as an alternative to amniocentesis after 20 weeks' gestation to confirm an abnormal karyotype in a DC pregnancy, when selective feticide is considered a few weeks after the initial procedure. Nowadays diagnostic cordocentesis is not recommended as routine procedure except for suspected hematologic disease cases. ${ }^{63}$

\section{TWIN-TO-TWIN TRANSFUSION SYNDROME}

\section{Introduction}

Monochorionic pregnancies have a perinatal mortality rate nearly twice as high as dichorionic twins ( 2.8 vs $1.6 \%)$ and four times as high as singleton pregnancies (2.8 vs $0.7 \%$ ). Monochorionic diamniotic (MCDA) pregnancies are at increased risk of developing twin to twin transfusion syndrome (TTTS). About 8 to $10 \%$ of these MCDA pregnancies will develop TTTS with potentially catastrophic complications for the embryos (Table 1). ${ }^{90-92}$

The pathophysiology of TTTS is based on the angioarchitecture of the placenta. The reason for the development of TTTS in MCDA pregnancies is attributed to vascular connections between the embryos, which are embedded in their common placenta. ${ }^{64}$ By definition all MCDA twins have connections of their circulatory systems through anastomosis in the placenta. Placental anastomosis can be arterioarterial (AA), arteriovenus (AV) and venovenous (VV). Arterioarterial and VV anastomosis are

Table 1: Staging of TTTS (Quintero criteria)

\begin{tabular}{|c|c|c|}
\hline & $\begin{array}{l}\text { Ultrasound } \\
\text { parameter }\end{array}$ & $\begin{array}{l}\text { Categorical } \\
\text { criteria }\end{array}$ \\
\hline Stage I & $\begin{array}{l}\text { MVP of amniotic } \\
\text { fluid }\end{array}$ & $\begin{array}{l}\text { MVP }<2 \mathrm{~cm} \text { in donor sac, } \\
M V P>8 \mathrm{~cm} \text { in recipient sac }\end{array}$ \\
\hline Stage II & Fetal bladder & $\begin{array}{l}\text { Non-visualization of fetal } \\
\text { bladder after } 60 \text { minutes } \\
\text { of observation }\end{array}$ \\
\hline Stage III & $\begin{array}{l}\text { Umbilical a., DV } \\
\text { and umbilical } \\
\text { v. waveform }\end{array}$ & $\begin{array}{l}\text { Absent or reversed } \\
\text { umbilical artery end } \\
\text { diastolic flow, reversed } \\
\text { DV a-wave flow, pulsatile } \\
\text { umbilical vein flow }\end{array}$ \\
\hline Stage IV & Fetal hydrops & $\begin{array}{l}\text { Hydrops in one or both } \\
\text { twins }\end{array}$ \\
\hline Stage $\mathrm{V}$ & $\begin{array}{l}\text { Absent fetal } \\
\text { cardiac activity }\end{array}$ & $\begin{array}{l}\text { Fetal demise in one or } \\
\text { both twins }\end{array}$ \\
\hline
\end{tabular}

TTTS: Twin to twin transfusion syndrome; MVP: maximum vertical pocket; a.: artery; v.: vein; DV: ductus venosus; Quintero criteria modified according to SMFM Clinical Guidelines by Simpson ${ }^{64-65}$ 
Table 2: Ultrasound findings predictive of twin to twin transfusion syndrome

\begin{tabular}{ll}
\hline First & Discordance of CRL of the two twins \\
trimester & Pathologic DV (reversal of A-wave) \\
& NT $>95$ th centile or NT difference $>20 \%{ }^{69,70}$ \\
Second & Discordance of AC $>20 \%{ }^{67}$ \\
trimester & $\begin{array}{l}\text { Placental echogenicity } \\
\text { Membrane folding }\end{array}$ \\
& Velamentous cord insertion for the donor twin ${ }^{74}$ \\
\hline
\end{tabular}

CRL: crown-rump length; DV: ductus venosus; NT: nuchal translucency; AC: abdominal circumference; Table is according to SMFM Clinical Guidelines by L Simpson ${ }^{64}$

superficial and bidirectional located on the surface of the chorionic plate, forming direct communications between the arteries and the veins from the two fetal circulations, thus, allowing flow in either direction depending on the relative interfetal vascular pressure gradients. ${ }^{74,93}$ For the development of TTTS responsible are the deeper anastomoses, which are called arteriovenous (AV) anastomoses, which are located at the capillary level deep within a shared cotyledon. The blood flow in these anastomoses is mostly bidirectional, allowing blood transportation from one twin to another. However in some cases, this blood flow through the anastomosis is directed only from one twin to another, leading to a donor-recipient relationship between the two embryos, which gradually results to the development of TTTS. ${ }^{94-96}$ It is believed that the presence of bidirectional AA anastomoses is protective against the development of TTTS, as the placentas of MCDA pregnancies that do not develop TTTS have AA anastomoses $(84 \%)$, while the placentas of TTTS cases have less AA anastomoses (20-30\%). Apart from the anastomoses discordant placental function may play a role in the development of TTTS and also other factors involving the regulating endocrine system of renin-angiotensin (Table 2). ${ }^{97-99}$

\section{Treatment Methods}

The progression of TTTS is variable and most cases diagnosed at stage I remain stable or regress without the need of invasive interventions. However, more severe cases (stage III-IV), have a very high perinatal loss rate $(70-100 \%)$, if they remain untreated, particularly when it presents 26 weeks. It is estimated that TTTS accounts for up to $17 \%$ of the total perinatal mortality in twins, and for about $50 \%$ of all perinatal deaths in MCDA twins. If appropriate treatment is not offered death of one fetus is possibly unavoidable, with high risk of fetal demise of the second twin either antenatally (10\% risk of fetal death) or postnatally (10-30\% risk of neonatal neurological handicap). Survival of one twin ranges between 15 and $70 \%$, depending on the gestational age at diagnosis and severity of disease. ${ }^{100-103}$
The invasive procedures for the treatment of TTTS include: amnioreduction, amniotic septostomy of the intertwin membrane, umbilical cord occlusion leading to selective reduction and laser treatment of placental anastomoses. Before proceeding to any invasive method for the treatment of TTTS, it is crucial that appropriate counseling is offered to the parents who have a pregnancy complicated with TTTS, so that they understand the risks of each method, what the method involves and what is the natural history and the prognosis of TTTS. ${ }^{76,78,104}$

Amnioreduction aims to decrease the amniotic fluid from amniotic sac of the recipient embryo, in order to reduce the intra-amniotic and placental intravascular pressures, improving in that way the placental circulation and at the same time to relieve the feeling of discomfort that is caused by the increased amniotic fluid to the pregnant woman and possibly decrease the risk of preterm delivery. ${ }^{105,106}$ Amnioreduction is preferably done when the MVP is $>8 \mathrm{~cm}$, and depending on the physician performing the procedure, it is conducted by draining about 1 to 2 liters of amniotic fluid, usually slowly, or by watching the MVP decreasing under eight (preferably 5-6) with direct ultrasound observation. ${ }^{64}$ The procedure of amnioreduction itself is technically straightforward and similar to amniocentesis, using a 20 or 18 gauge syringe, and can be performed after 14 weeks. However, it does not treat the cause of TTTS, as it does not interfere with the vascular basis of the condition nor prevents the risk of neurological damage in case of single embryo demise. ${ }^{1,107,108}$ It offers a possible relief of the symptoms and as it does not treat the cause of the problem in most cases amniotic fluid in the side of the recipient reaccumulates and more than one procedures of amnioreduction is most likely to be needed (70\%) increasing at the same time the risk of infection, preterm labor and preterm rupture of membranes, placental abruption, fetal trauma and fetal death and in more rare cases with necrotizing enterocolitis and renal failure. ${ }^{78} \mathrm{~A}$ procedure related risk of delivery has been estimated to $4 \%$. Amnioreduction appears to be effective in mild cases of TTTS, with a therapy failure of one every three cases and over half of the treated patients still experiencing loss of one or both fetuses. The overall perinatal survival rate for cases $<26$ weeks has been calculated approximately to $57 \% .{ }^{109-112}$

Septostomy is a method that has been suggested for the treatment of TTTS and aims to the intentional division of the intertwin membrane, so that amniotic fluid can pass from the recipient to the donor embryo, and theoretically the volumes of the amniotic fluid of the two embryos can reach similar levels in the two sacs. ${ }^{113}$ The disadvantage of this method is that similarly to amnioreduction it does 
Table 3: Septostomy vs amnioreduction ${ }^{75}$

\begin{tabular}{lll}
\hline Variable & $\begin{array}{l}\text { Septostomy } \\
(n=35)\end{array}$ & $\begin{array}{l}\text { Amnioreduction } \\
(n=36)\end{array}$ \\
\hline $\begin{array}{l}\text { Mean GA at delivery } \\
\text { (weeks) }\end{array}$ & 30.7 weeks & 29.5 weeks \\
$\begin{array}{l}\text { Survival of at least } 1 \\
\text { twin at 28 days of age }\end{array}$ & $80 \%(28 / 35)$ & $78 \%(28 / 36)$ \\
$\begin{array}{l}\text { All perinatal deaths up to } \\
28 \text { days of age }\end{array}$ & $30 \%(21 / 70)$ & $36 \%(26 / 72)$ \\
\hline $\begin{array}{l}\text { GA: gestational age; Table is according to SMFM clinical guidelines } \\
\text { by L Simpson }\end{array}$
\end{tabular}

not offer treatment of the causative pathway of TTTS. However, few data are available to support this technique and the pathophysiological explanation remains to be demonstrated. ${ }^{114}$ Amniotic septostomy, is currently not proposed as a method for treatment of TTTS, since it does not improve the prognosis of the pregnancy and what is more it can cause iatrogenic conversion of the pregnancy from diamniotic to monoamniotic, adding the risks of such a condition (e.g. cord entanglement) (Table 3). ${ }^{104}$

The presence of placental anastomoses and circulatory communications between the two embryos makes the injection of any lethal agent for selective fetocide unsuitable. ${ }^{115}$ Thus, complete occlusion of both the arterial and venous flows in the umbilical cord of one of the twins (usually the recipient) is more appropriate. Umbilical cord occlusion for selective fetocide refers to the interruption of the blood flow in the umbilical cord of one of the twins, causing the death of this particular twin, aiming to improve the outcome of the other surviving twin, as there will be no second twin and no intertwin communication of blood flow. ${ }^{116}$ The occlusion of the umbilical cord leaves the vessels between the donor and placenta intact. ${ }^{117}$ Bipolar coagulation of the umbilical cord is the most preferable method for selective fetocide in monochorionic twin pregnancies, but other methods have also been suggested (embolization with sclerosant agents, fetoscopic cord ligation, laser coagulation etc). ${ }^{115}$ The procedure is usually carried out with the help of ultrasound direct vision, using 2 to $3 \mathrm{~mm}$ bipolar forceps, which is inserted through an adapted cannula. The procedure does not last long, it needs a single port entry and can be performed after 26 weeks of pregnancy. Confirmation of successful coagulation of the cord is done with color Doppler when absence of flow in the umbilical cord is seen. By definition the maximum expected overall survival rate for twins after umbilical cord occlusion is $50 \%$, and as a result it is usually reserved for severe TTTS stages (III or IV). ${ }^{118-120}$

The application of any invasive procedure (amnioreduction, septostomy) before starting treatment with fetoscopy and laser photocoagulation may decrease the visibility because of bleeding, chorioamnion separation, inadvertent septostomy, or membrane rupture. ${ }^{64}$
In 1990, De Lia introduced the use of laser photocoagulation for the treatment of TTTS. Since then, the method has evolved and successfully studied in many studies. ${ }^{121}$ Aim of selective photocoagulation is to only coagulate the anastomoses that are responsible for the development of TTTS instead of coagulating all the placental vessels of the intertwin membrane. Laser surgery has shown better results than amnioreduction decreasing in some studies the perinatal death rate even by $20 \%$. The introduction of laser treatment for TTTS appears to improve the outcome of these pregnancies, showing a significant decrease of perinatal mortality and an improvement of neonatal outcome. Studies show that laser treatment for the treatment of TTTS appears to have better results and neonatal outcome than the more traditional methods of managing TTTS, such as amnioreduction, which has been more widely studied. Laser treatment for TTTS involves photocoagulating the vascular anastomoses crossing from one side of the placenta to the other. The proper use of ultrasound is of crucial importance for the completion of the procedure, as it is necessary first of all to identify and document the localization of the placenta, its vasculature and the anastomosis..$^{64}$ Also the endoscope for the coagulation is inserted in the uterus under ultrasound guidance. Laser coagulation is the only method that actually treats the cause of TTTS as it occludes the placental anastomoses that are responsible for the problem called TTTS. ${ }^{64,122}$ By ablating the anastomosis, when it is done appropriately laser treatment results in the complete separation of the placenta in two functionally two placentas, and the 'new' placenta that results at the end of the procedure behaves as two placentas, so that the pregnancy can be characterized as dichorionic. For the proper performance of laser treatment very important is the adequate visualization of the vascular equator that separates the cotyledons of one twin from the other. Also important is the selective coagulation of anastomoses rather than non-selective ablation of all vessels crossing the separating membrane as it appears to lead to fewer procedure-related fetal losses. The concept behind selective photocoagulation is to only coagulate the vessels participating in the syndrome instead of all vessels crossing the intertwin membrane. Some of the criteria for application of laser treatment are gestational age between 15 and 26 weeks, recipient twin with distended fetal bladder and MVP $>8.0 \mathrm{~cm}$, donor twin with MVP $<2.0 \mathrm{~cm}$ and nonvisualized fetal bladder. ${ }^{64,123-125}$

Recent data show that laser treatment for TTTS appears to be a better method for the management of severe cases of TTTS (Quintero stages III-IV), than the (Tables 4 and 5) older methods, such as amnioreduction. The Eurofetus trial studied the efficacy of laser treatment 
Table 4: Laser treatment for TTTS vs amnioreduction (data from Eurofetus) ${ }^{76,77}$

\begin{tabular}{lll}
\hline & $\begin{array}{l}\text { Laser } \\
N=72 \\
\text { twin pregnancies }\end{array}$ & $\begin{array}{l}\text { Amnioreduction } \\
N=70 \text { twin } \\
\text { pregnancies }\end{array}$ \\
\hline GA at delivery (wks) & 33.3 & 29.0 \\
$\begin{array}{l}\text { Survival of at least one } \\
\text { twin at } 6 \text { months of age }\end{array}$ & $76 \%(55 / 72)$ & $56 \%(36 / 70)$ \\
$\begin{array}{l}\text { All perinatal deaths at } \\
6 \text { months of age }\end{array}$ & $44 \%(63 / 144)$ & $61 \%(86 / 140)$ \\
$\begin{array}{l}\text { CPLM at } 6 \text { months of } \\
\text { age }\end{array}$ & $6 \%(8 / 144)$ & $14 \%(20 / 140)$ \\
$\begin{array}{l}\text { Alive, without neurolo- } \\
\text { gical symptoms at } \\
6 \text { months of age }\end{array}$ & $52 \%(75 / 144)$ & $31 \%(44 / 140)$ \\
$\begin{array}{l}\text { Normal neurologic } \\
\text { development at } 6 \text { years }\end{array}$ & $82 \%(60 / 73)$ & $70 \%(33 / 47)$ \\
\hline
\end{tabular}

TTTS: Twin to twin transfusion syndrome, GA: gestational age, wks: weeks, CPLM: cystic periventricular leucomalacia; Table is according to SMFM Clinical Guidelines by L Simpson ${ }^{64}$

in severe cases of TTTS before 26 weeks of gestational age and showed neonatal survival of at least one twin and at of 6 months of age in $76 \%$ of cases, compared to a corresponding lower $56 \%$ in cases that were treated with the method of amnioreduction. ${ }^{76}$ Further data analysis in a stage-adjusted series suggested laser therapy resulted in a higher perinatal death rate than amnioreduction for TTTS cases of stages I to II. For the treatment of TTTS in cases of stage I, there are no randomized trial designed exclusively for the efficacy of treatment methods for this particular stage. Pregnancies of stage I TTTS are most frequently managed expectantly. This is indeed justified as most of these cases (75\%) remain stable and do not progress to a higher level or regress spontaneously. ${ }^{64}$ However, in 10 to $30 \%$ of stage I cases there is a progression to a more severe stage, interventions and other methods of management than conservative one have been evaluated. Amnioreduction is the case that has been studied more widely for stages I and II and in 20 to $30 \%$ of cases they were treated completely with only treatment method amnioreduction. This rate that is not significantly different than the correspondant
Table 5: Laser treatment for TTTS vs Amnioreduction (data from NICHD Study) ${ }^{78}$

\begin{tabular}{lll}
\hline & $\begin{array}{l}\text { Laser } \\
N=20 \text { twin } \\
\text { pregnancies }\end{array}$ & $\begin{array}{l}\text { Amnioreduction } \\
N=20 \text { twin } \\
\text { pregnancies }\end{array}$ \\
\hline $\begin{array}{l}\text { GA at delivery (wks) } \\
\text { Survival of at least one }\end{array}$ & 30.5 & 30.2 \\
twin at 30 days of age & $65 \%(13 / 20)$ & $75 \%(15 / 20)$ \\
$\begin{array}{l}\text { All perinatal deaths at 30 } \\
\text { days of age }\end{array}$ & $55 \%(22 / 40)$ & $40 \%(16 / 40)$ \\
$\begin{array}{l}\text { Recipient twin fetal } \\
\text { mortality }\end{array}$ & $70 \%(14 / 20)$ & $35 \%(7 / 20)$ \\
\hline
\end{tabular}

TTTS: twin to twin transfusion syndrome, GA: gestational age, wks: weeks; Table is according to SMFM Clinical Guidelines by L Simpson ${ }^{64}$

rate of expectant management, especially for stage I. ${ }^{126-128}$ Current evidence is not sufficient to determine optimal treatment for early stage I of TTTS due to the small number of cases treated at this stage to date (Table 6).

Evidence show that neonatal outcome and also morbidity and mortality risks are improved when any of the three invasive techniques is applied (amnioreduction, endoscopic laser treatment, septostomy) when compared to studies where no treatment was applied, and that is valid regardless of the Quintero staging. ${ }^{129}$ Survival of neonates in cases of TTTS that where treated with amnioreduction is around 37 to $60 \%$ with the highest survival rate calculated as $82 \%$ in a study. Amnioreduction is not without side effects and the neurologic impairment after serial amnioreductions has been calculated to 17 to $33 \%$. The corresponding numbers for laser photocoagulation, are neonatal survival rate about 55 to $73 \%$ and neurologic impairment about 4 to $18 \%$. Studies have shown an $80 \%$ survival rate in cases that were treated with septostomy (Table 7).

In a recent study, Van Mieghem et al studied 97 monochorionic diamniotic pregnancies and tried to identify predictors of TTTS and selective intrauterine growth restriction (sIUGR) in cases of moderate amniotic fluid discordance. The outcome of MCDA twins with discordance in the amniotic fluid could not be predicted, however, they managed to identify high-risk and low-

Table 6: Outcomes of pregnancies with TTTS after laser treatment

\begin{tabular}{|c|c|c|c|c|c|c|c|c|c|c|}
\hline Study & Years & $N$ & Stage III & Stage IV & $\begin{array}{l}\text { GA at } \\
\text { delivery } \\
\text { (wks) }\end{array}$ & $\begin{array}{l}2 \\
\text { surviving } \\
\text { embryos }\end{array}$ & $\begin{array}{l}1 \\
\text { surviving } \\
\text { embryo }\end{array}$ & $\begin{array}{l}0 \\
\text { surviving } \\
\text { embryo }\end{array}$ & $\begin{array}{l}\text { Neonatal } \\
\text { death }\end{array}$ & $\begin{array}{l}\text { Overall } \\
\text { perinatal } \\
\text { survival }\end{array}$ \\
\hline Ville et $\mathrm{al}^{80}$ & 1998 & 132 & $12 \%$ & $10 \%$ & $\mathrm{~N} / \mathrm{A}$ & $36 \%$ & $38 \%$ & $27 \%$ & $4.5 \%$ & $55 \%$ \\
\hline Hecher et al ${ }^{81}$ & 2000 & 200 & N/A & N/A & $33.7-34.4$ & $50 \%$ & $30 \%$ & $20 \%$ & $3.8 \%$ & $65 \%$ \\
\hline Yamamoto et al ${ }^{79}$ & 2005 & 175 & $37 \%$ & $4 \%$ & $\mathrm{~N} / \mathrm{A}$ & $35 \%$ & $38 \%$ & $27 \%$ & $5.4 \%$ & $54 \%$ \\
\hline Huber et $\left.a\right|^{82}$ & 2006 & 200 & $40 \%$ & $5 \%$ & 34.3 & $59 \%$ & $24 \%$ & $17 \%$ & $4.8 \%$ & $72 \%$ \\
\hline Quintero et $\mathrm{al}^{84}$ & 2007 & 137 & $44 \%$ & $12 \%$ & 33.7 & $74 \%$ & $17 \%$ & $10 \%$ & $11.3 \%$ & $83 \%$ \\
\hline Morris et al ${ }^{83}$ & 2010 & 164 & $79 \%$ & $17 \%$ & 33.2 & $38 \%$ & $46 \%$ & $15 \%$ & $6.4 \%$ & $62 \%$ \\
\hline Totals & & 1008 & $35 \%$ & $7 \%$ & & $49 \%$ & $32 \%$ & $19 \%$ & $5.8 \%$ & $65 \%$ \\
\hline
\end{tabular}

TTTS: twin to twin transfusion syndrome; N/A: not applicable; GA: gestational age; wks: weeks; N: number; Table is according to SMFM Clinical Guidelines by L Simpson ${ }^{64}$ 
Invasive Procedures in Monochorionic Twins

Table 7: Neonatal neurological outcome after laser treatment for TTTS

\begin{tabular}{|c|c|c|c|c|c|c|}
\hline Study & Years & $N$ & $\begin{array}{l}\text { GA at } \\
\text { assessment }\end{array}$ & $\begin{array}{l}\text { Normal } \\
\text { development }\end{array}$ & $\begin{array}{l}\text { Major } \\
\text { neurological } \\
\text { abnormality }\end{array}$ & $\begin{array}{l}\text { Minor } \\
\text { neurological } \\
\text { abnormality }\end{array}$ \\
\hline Sutcliffe et al ${ }^{85}$ & 2001 & 66 & 24 & $\mathrm{~N} / \mathrm{A}$ & $9 \%$ & $\mathrm{~N} / \mathrm{A}$ \\
\hline Banek et al ${ }^{86}$ & 2003 & 89 & 22 & $78 \%$ & $11 \%$ & $11 \%$ \\
\hline 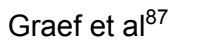 & 2006 & 167 & 38 & $87 \%$ & $6 \%$ & $7 \%$ \\
\hline Lenclen et $\mathrm{al}^{88}$ & 2009 & 88 & 24 & $89 \%$ & $5 \%$ & $7 \%$ \\
\hline Lopriore et $\mathrm{al}^{89}$ & 2009 & 278 & 24 & $82 \%$ & $18 \%$ & $\mathrm{~N} / \mathrm{A}$ \\
\hline
\end{tabular}

TTTS: twin to twin transfusion syndrome; N/A: not applicable; GA: gestational age; wks: weeks; N: number; Table is according to SMFM Clinical Guidelines by L Simpson ${ }^{64}$

risk subgroups for TTTS, based on the severity of fluid discordance and gestational age..$^{130}$

\section{Complications of Laser Treatment}

For severe TTTS laser treatment is the first-line of treatment for severe TTTS. The survival rates after TTTS for at least one twin is reported in studies around 75 to $85 \% .{ }^{64}$ As with any invasive prenatal procedure risks and complications have been documented, such as increased risk of preterm premature rupture of membranes (PPROM) ${ }^{131}$ The rupture of membranes has been reported in more than 1:4 of the cases that underwent TTTS treatment $(28 \%)$ and a similar rate of these cases has been associated with about the same percentage of preterm delivery ( $30 \%$ ) before 32 weeks. Recent studies report that there is a $10 \%$ risk of PPROM with a 10 to $30 \%$ risk of fetal death, of at least one of the two twins..$^{64,76,81,122,132}$ Another recognized complication of laser treatment is unintentional septostomy of the intertwin membrane. Usually, it can be caused by difficult entry in the uterine cavity close to the donor embryo, where because of the anhydramnios the membrane may not be visible and perforated. Another reason is by coagulation of anastomoses close to the intertwin membrane. ${ }^{131}$ The formation of pseudoamniotic band syndrome (PABS) has been reported as a possible complication of treatment for TTTS. Cruz-Martinez et al studied 414 MCDA pregnancies who underwent laser treatment for TTTS. The overall survival rate was $73 \%$ for both twins and $92 \%$ for the survival of at least one twin. Inadvertent septostomy after laser treatment was noted in 30 cases 1 week after the operation, and in eight cases it was diagnosed after delivery because of PABS, which was manifested with limb constriction. The authors concluded that inadvertent septostomy after laser treatment for TTTS occurs in about $7 \%$ of cases and is associated with an increased risk of PABS and of adverse perinatal outcome. ${ }^{131}$

Yamamoto et al noted that laser treatment for TTTS increases the risk of intrauterine growth restriction
(IUGR). ${ }^{79}$ The pathophysiological pathway that has been described for the cause of development of IUGR after laser treatment has to do with the unintentional damage of placental functional mass and necrosis caused by devascularization after laser therapy. The risk of developing IUGR regards one or both twins, and eventually if restriction occurs early in pregnancy and persists, fetal death may occur. ${ }^{79}$ When IUGR is diagnosed before the application of laser treatment, especially when absent or reversed end-diastolic flow in the umbilical artery is noted, there is a 20 to $40 \%$ increased risk of postoperative fetal death of one of the two twins, mainly the donor. ${ }^{64,133-134}$ Postoperatively fetal demise of the recipient twin is more common when reversed a-wave in the ductus venosus, or hydrops occurs. ${ }^{135}$ Some studies show improved survival rate of the recipient twin with administration of nifedipine 24 to 48 hours prior to laser photocoagulation, especially in cases with twin to twin transfusion syndrome cardiomyopathy. ${ }^{136}$ If recipient cardiomyopathy exists the time needed for cardiac function back to normal levels after laser treatment is in average 4 weeks. ${ }^{137}$ Abnormalities of the pulmonary valve, which are seen mainly in the recipient twins, have also been noted to improve after laser decreasing the number of fetuses needing surgery after delivery. ${ }^{137}$ Eighty seven percent recipient twins who survived after laser treatment for severe TTTS, were reported to have normal cardiac function at about 2 years after delivery. ${ }^{138}$

Other complications that have been documented with laser treatment involve amniotic fluid leakage into the maternal peritoneal cavity, vaginal bleeding, placental abruption and chorioamnionitis. ${ }^{64,79}$ The instruments used for laser photocoagulation are of larger diameter than the spinal needle that are usually preferred for amnioreduction or even septostomy and even that factor is enough to increase the risk of complications. What is more laser therapy is a much more invasive procedure than the other two mentioned above, increasing the risks of complications at least three times, ${ }^{64,76}$ giving an overall risk of complications about $3 \% .{ }^{76}$ Despite these 
risks, fetoscopic laser photocoagulation appears to be the optimal treatment for stage II to IV TTTS. The risks of each invasive procedure is something that patients should be aware of and all the advantages and disadvantages of each procedure should be discussed with them before taking the final decision about the method of treatment. What is more, it should be noted that even with laser therapy, intact survival of both twins with TTTS is only about $50 \%{ }^{64}$

\section{Outcome of Treatment-Neonatal Follow-up}

Studies regarding the long-term neurodevelopmental outcome in cases of TTTS that had conservative management showed a high rate of perinatal mortality and a high rate of major neurodevelopmental impairment. The long-term outcomes for the survivors with TTTS were good when survivors were delivered after 29 weeks of gestation. ${ }^{139}$ It appears though that severe TTTS cases have a high percentage of major neurodevelopmental impairment irrespectively of whether they are treated conservatively or with laser photocoagulation.

The percentage of long-term neurologic complications in survivor neonates after laser-treatment for stage I TTTS has been reported about $3 \%$. The corresponding overall rate for any stage TTTS is about 5 to $20 \% .{ }^{64}$ This risk of neurologic impairment appears to be comparable both between donor and recipient and survivors after laser or amnioreduction treatment. ${ }^{64,85,87-89}$ The detection rate of severe brain lesions (e.g. periventricular leukomalacia, intraventricular hemorrhage grade III or IV) in fetuses during pregnancy is much higher in pregnancies affected by TTTS (10\%) compared to MCDA twins without TTTS $(2 \%) .{ }^{64}$ Advanced gestational age at the time of laser surgery, low birth weight, and severe TTTS, are risk factors that further increase the possibility of adverse neurological outcome of the surviving neonate. ${ }^{64,89}$ Fetal MRI after fetal death of one of the twins who were treated with laser for TTTS can detect brain injury much earlier than ultrasound, ${ }^{64,140,141}$ and MRI imaging has been suggested by some centers pre- and post-treatment for TTTS, and for cases complicated by single twin demise. ${ }^{64,132,141-143}$

Laser photocoagulation for at least severe cases of TTTS appears to be the best possible option for treatment. However, parents and physicians need to have in mind that TTTS is a very high risk case in terms of perinatal outcomes and that the possibility of death of at least one of the two twins is very high, about 30 to $50 \%$ and that even after survival from treatment for TTTS there is a significant risk of long-term neurological impairment ranging from 5 to $20 \%{ }^{64}$

\section{REFERENCES}

1. Antsaklis A, Partsinevelos G. Invasive diagnostic procedures in multiple pregnancies. Gynaecol Perinatol 2008;17(1):15-21

2. Lewi L, Van Schoubroeck D, Gratacós E, Witters I, Timmerman D, Deprest J. Monochorionic diamniotic twins: complications and management options. Curr Opin Obstet Gynecol 2003 Apr;15(2):177-194.

3. Dubé J, Dodds L, Armson BA. Does chorionicity or zygosity predict adverse perinatal outcomes in twins? Am J Obstet Gynecol 2002 Mar;186(3):579-583.

4. Derom R, Orlebeke J, Eriksson A. The epidemiology of multiple births in Europe. In: Keith LG, Papiernik E, Keith DM, Luke B, editors. Multiple pregnancy: epidemiology, gestationa and perinatal outcome. New York: Parthenon; 1995. p. 145-162.

5. Dudenhausen J. Management of multiple pregnancy. Donald School J Ultrasound in Obstet Gynecol 2009;3(3):45-49.

6. Lewi L, Blickstein I, Van Schoubroeck D, Gloning KP, Casteels M, Brandenburg H, Fryns JP, Deprest J. Diagnosis and management of heterokaryotypic monochorionic twins. Am J Med Genet A 2006 Feb 1;140(3):272-275.

7. Machin GA. The phenomenon of monozygosity. In: Blickstein I, Keith LG, editors. Multiple pregnancy. Epidemiology, gestation and perinatal outcome. Oxon, UK: Taylor and Francis; 2005 p. 201-213.

8. Rogers JG, Voullaire L, Gold H. Monozygotic twins discordant for trisomy 21. Am J Med Genet 1982;11(2):143-146.

9. Dallapiccola B, Stomeo C, Ferranti G, Di Lecce A, Purpura M. Discordant sex in one of three monozygotic triplets. J Med Genet 1985;22(1):6-11.

10. Perlman EJ, Stetten G, Tuck-Müller CM, et al. Sexual discordance in monozygotic twins. Am J Med Genet 1990; 37(4):551-557.

11. Schmid O, Trautmann U, Ashour H, Ulmer R, Pfeiffer RA, Beinder E. Prenatal diagnosis of heterokaryotypic mosaic twins discordant for fetal sex. Prenat Diagn 2000;20(12): 999-1003.

12. Wachtel SS, Somkuti SG, Schinfeld JS. Monozygotic twins of opposite sex. Cytogenet Cell Genet 2000;91(1-4):293-295.

13. Lespinasse J, Gicquel C, Robert M, Le Bouc Y. Phenotypic and genotypic variability in monozygotic triplets with Turner syndrome. Clin Genet 1998;54(1):56-59.

14. Nieuwint A, Van Zalen-Sprock R, Hummel P et al. Identical' twins with discordant karyotypes. Prenat Diagn 1999; 19(1):72-76.

15. Vink J, Wapner R, D'Alton ME. Prenatal diagnosis in twin gestations. Semin Perinatol 2012 Jun;36(3):169-174.

16. Evaluation of chorionic villus sampling safety: $\mathrm{WHO} / \mathrm{PAHO}$ consultation on CVS. Prenat Diagn 1999;19(9):97-99.

17. Rodis JF, Egan JF, Craffey A, Ciarleglio L, Greenstein RM, Scorza WE. Calculated risk of chromosomal abnormalities in twin gestations. Obstet Gynecol 1990;76(6):1037-1041.

18. Fisk NM, Bennett PR. Prenatal determination of chorionicity and zygocity. In: Ward RH, Whittle W, editors. Multiple Pregnancy. London: RCOG Press; 1995. p. 56-66.

19. Matias A, Montenegro N, Blickstein I. Down syndrome screening in multiple pregnancies. Obstet Gynecol Clin North Am 2005;32(1):81-96.

20. Millaire M, Bujold E, Morency AM, Gauthier RJ. Midtrimester genetic amniocentesis in twin pregnancy and the risk of fetal loss. J Obstet Gynaecol Can 2006 Jun;28(6):512-518. 
21. Cahill AG, Macones GA, Stamilio DM, Dicke JM, CraneJP, Odibo AO. Pregnancy loss rate after mid-trimester amniocentesis in twin pregnancies. Am J Obstet Gynecol 2009 Mar;200(3):257.e1-6.

22. Baldwin VJ. Anomalous development in twins. In: Pathology of multiple pregnancies. New York: Springer-Verlag; 1994. p. 169-197.

23. Little J, Bryan E. Congenital anomalies in twins. Semin Perinatol 1986;10:50-64.

24. Bryan E, Little J, Burn J. Congenital anomalies in twins. Baillieres Clin Obstet Gynaecol 1987;1(3):697-721.

25. Audibert F, Gagnon A; Genetics Committee of the Society of Obstetricians and Gynaecologists of Canada; Prenatal Diagnosis Committee of the Canadian College of Medical Geneticists. Prenatal screening for and diagnosis of aneuploidy in twin pregnancies. J Obstet Gynaecol Can 2011 Jul;33(7):754-767.

26. Elias S, Gerbie AB, Simpson JL, Nadler HL, Sabbagha RE, Shkolnik A. Genetic amniocentesis in twin gestations. Am J Obstet Gynecol 1980;15;138(2):169-174.

27. Cragan JD, Martin ML, Khoury MJ, Fernhoff PM. Dye use during amniocentesis and birth defects. Lancet 1993;341 (8856):1352.

28. Nicolini U, Monni G. Intestinal obstruction in babies exposed in utero to methylene blue. Lancet 1990;336(8725):1258-1259.

29. Kidd SA, Lancaster PA, Anderson JC, et al. Fetal death after exposure to methylene blue dye during mid-trimester amniocentesis in twin pregnancy. Prenat Diagn 1996;16(1): 39-47.

30. McEnerney JK, McEnerney LN. Unfavorable neonatal outcome after intraamniotic injection of methylene blue. Obstet Gynecol 1983;61(Suppl.3):35S-37S.

31. McFadyen I. The dangers of intra-amniotic methylene blue. Br J Obstet Gynaecol 1992;99(2):89-90.

32. van der Pol JG, Wolf H, Boer K, et al. Jejunal atresia related to the use of methylene blue in genetic amniocentesis in twins. Br J Obstet Gynaecol 1992 Feb;99(2):141-143.

33. Vincer MJ, Allen AC, Evans JR, Nwaesei C, Stinson DA. Methylene-blue-induced hemolytic anemia in a neonate. Can Med Ass J 1987;136(5):503-504.

34. Antsaklis A, Souka AP, Daskalakis G, Kavalakis Y, Michalas S. Second-trimester amniocentesis vs chorionic villus sampling for prenatal diagnosis in multiple gestations. Ultrasound Obstet Gynecol 2002;20(5):476-481.

35. Taylor MJ, Fisk NM. Prenatal diagnosis in multiple pregnancy. Baillieres Best Pract Res Clin Obstet Gynaecol 2000; 14(4):663-675.

36. Weisz $\mathrm{B}$, Rodeck $\mathrm{CH}$. Invasive diagnostic procedures in twin pregnancies. Prenat Diagn 2005;25(9):751-758.

37. Jeanty P, Shah D, Roussis P. Single-needle insertion in twin amniocentesis. J Ultrasound Med 1990;9(9):511-517.

38. Megory E, Weiner E, Shalev E, Ohel G. Pseudomonoamniotic twins with cord entanglement following genetic funipuncture. Obstet Gynecol 1991;78(5 Pt 2):915-917.

39. Buscaglia M, Ghisoni L, Bellotti M, Marconi AM, Zamerini $\mathrm{P}$, Stripparo L, et al. Genetic amniocentesis in biamniotic twin pregnancies by a single transabdominal insertion of the needle. Prenat Diagn 1995;15(1):17-19.

40. van VugtJM, Nieuwint A, van Geijn HP. Single-needle insertion: an alternative technique for early second-trimester genetic $t w i n$ amniocentesis. Fetal Diagn Ther 1995;10(3):178-181.
41. Cirigliano V, Cañadas P, Plaja A, Ordoñez E, Mediano C, Sánchez A, et al. Rapid prenatal diagnosis of aneuploidies and zygosity in multiple pregnancies by amniocentesis with single insertion of the needle and quantitative fluorescent PCR. Prenat Diagn 2003;23(8):629-633.

42. Sebire NJ, Noble PL, Odibo A, Malligiannis P, Nicolaides $\mathrm{KH}$. Single uterine entry for genetic amniocentesis in twin pregnancies. Ultrasound Obstet Gynecol 1996;7(1):26-31.

43. Acosta-Rojas R, Becker J, Munoz-Abellana B, et al. Twin chorionicity and the risk of adverse perinatal outcome. Int J Gynaecol Obstet 2007;96(2):98-102.

44. Bahado-Singh R, Schmitt R, Hobbins JC. New technique for genetic amniocentesis in twins. Obstet Gynecol 1992;79(2): 304-307.

45. Palle C, Andersen JW, Tabor A, Lauritsen JG, Bang J, Philip $\mathrm{J}$. Increased risk of abortion after genetic amniocentesis in twin pregnancies. Prenat Diagn 1983;3(2):83-89.

46. Pijpers L, Jahoda MG, Vosters RP, Niermeijer MF, Sachs ES. Genetic amniocentesis in twin pregnancies. Br J Obstet Gynaecol 1988;95(4):323-326.

47. Anderson RL, Goldberg JD, Golbus MS. Prenatal diagnosis in multiple gestation: 20 years' experience with amniocentesis. Prenat Diagn 1991;11(4):263-270.

48. Yaron Y, Bryant-Greenwood PK, Dave N, et al. Multifetal pregnancy reductions of triplets to twins: comparison with nonreduced triplets and twins. Am J Obstet Gynecol 1999;180 (5):1268-1271.

49. Pruggmayer MR, Jahoda MG, Van der Pol JG, et al. Genetic amniocentesis in twin pregnancies: results of a multicenter study of 529 cases. Ultrasound Obstet Gynecol 1992;2(1):6-10.

50. Ghidini A, Lynch L, Hicks C, Alvarez M, Lockwood CJ. The risk of second-trimester amniocentesis in twin gestations: a case-control study. Am J Obstet Gynecol 1993;169(4):1013-1016.

51. Yukobowich E, Anteby EY, Cohen SM, Lavy Y, Granat M, Yagel S. Risk of fetal loss in twin pregnancies undergoing second trimester amniocentesis. Obstet Gynecol 2001;98: 231-234.

52. McLean LK, Evans MI, Carpenter RJ Jr, Johnson MP, Goldberg JD. Genetic amniocentesis following multifetal pregnancy reduction does not increase the risk of pregnancy loss. Prenat Diagn 1998;18(2):186-188.

53. Stephen JA, Timor-Tritsch IE, Lerner JP, Monteagudo A, Alonso CM. Amniocentesis after multifetal pregnancy reduction: is it safe? Am J Obstet Gynecol 2000;182(4):962-965.

54. Agarwal K, Alfirevic Z. Pregnancy loss after chorionic villus sampling and genetic amniocentesis in twin pregnancies: a systematic review. Ultrasound Obstet Gynecol 2012 Aug;40(2):128-134.

55. Brambati B, Terzian E, Tognoni G. Randomized clinical trial of transabdominal vs transcervical chorionic villus sampling methods. Prenat Diagn 1991;11(5):285-293.

56. Pergament E, Schulman JD, Copeland K, Fine B, Black SH, Ginsberg NA, et al. The risk and efficacy of chorionic villus sampling in multiple gestations. Prenat Diagn 1992;12: 377-384.

57. De Catte L, Liebaers I, Foulon W. Outcome of twin gestations after first trimester chorionic villus sampling. Obstet Gynecol 2000;96:714-720.

58. Fiddler M, Frederickson MC, Chen PX, Pergament E. Assessment of fetal status in multiple gestation pregnancies using interphase FISH. Prenat Diagn 2001;21:196-199. 
59. Jenkins TM, Wapner RJ. The challenge of prenatal diagnosis in twin pregnancies. Curr Opin Obstet Gynecol 2000;12(2): 87-92.

60. Weisz B, Rodeck $\mathrm{CH}$. Invasive diagnostic procedures in twin pregnancies. Prenat Diagn 2005;25(9):751-758.

61. Pergament E, Schulman JD, Copeland K, et al. The risk and efficacy of chorionic villus sampling in multiple gestations. Prenat Diagn 1992;12(5):377-384.

62. Antsaklis A, Gougoulakis A, Mesogitis S, Papantoniou N, Aravantinos D. Invasive techniques for fetal diagnosis in multiple pregnancy. Int J Gynaecol Obstet 1991;34(4):309-314.

63. Mikhailov A, Romanovsky A. Multiple Pregnancy under Ultrasound Umbrella. Donald School Journal of Ultrasound in Obstetrics and Gynecology. 2011 July-Sep;5(3): 219-230.

64. Simpson LL, Society for Maternal-Fetal Medicine. Twin-twin transfusion syndrome. Am J Obstet Gynecol 2013 Jan;208(1): 3-18.

65. Quintero RA, Morales WJ, Allen MH, Bornick PW, Johnson PK, Kruger M. Staging of twin-twin transfusion syndrome. J Perinatol 1999 Dec;19(8Pt 1):550-555.

66. Sebire NJ, Souka A, Skentou H, Geerts L, Nicolaides KH. Early prediction of severe twin to-twin transfusion syndrome. Hum Reprod 2000;15(9):2008-2010.

67. Lewi L, Lewi P, Diemert A, et al. The role of ultrasound examination in the first trimester and at 16 weeks' gestation to predict fetal complications in monochorionic diamniotic twin pregnancies. Am J Obstet Gynecol 2008;199(5):493.e1-7.

68. Sebire NJ, D’Ercole C, Hughes K, Carvalho M, Nicolaides KH. Increased nuchal translucency thickness at 10-14 weeks of gestation as a predictor of severe twin-to-twin transfusion syndrome. Ultrasound Obstet Gynecol 1997;10(2):86-89.

69. Kagan KO, Gazzoni A, Sepulveda-Gonzalez G, Sotiriadis A, Nicolaides KH. Discordance in nuchal translucency thickness in the prediction of severe twin-to-twin transfusion syndrome. Ultrasound Obstet Gynecol 2007;29(5):527-532.

70. Linskens IH, de Mooij YM, Twisk JW, Kist WJ, Oepkes D, van Vugt JM. Discordance in nuchal translucency measurements in monochorionic diamniotic twins as predictor of twin to-twin transfusion syndrome. Twin Res Hum Genet 2009; 12(6):605-610.

71. Maiz N, Staboulidou I, Leal AM, Minekawa R, Nicolaides KH. Ductus venosus Doppler at 11 to 13 weeks of gestation in the prediction of outcome in twin pregnancies. Obstet Gynecol 2009;113(4):860-865.

72. Matias A, Montenegro N, Loureiro T, et al. Screening for twin-twin transfusion syndrome at 11-14 weeks of pregnancy: the key role of ductus venosus blood flow assessment. Ultrasound Obstet Gynecol 2010;35(2):142-148.

73. Kusanovic JP, Romero R, Gotsch F, et al. Discordant placental echogenicity: a novel sign of impaired placental perfusion in twin-twin transfusion syndrome? J Matern Fetal Neonatal Med 2010;23(1):103-106.

74. De Paepe ME, Shapiro S, Greco D, et al. Placental markers of twin-to-twin transfusion syndrome in diamnioticmonochorionic twins: a morphometric analysis of deep artery-to-vein anastomoses. Placenta 2010;31(4):269-276.

75. Bajoria R, Sullivan M, Fisk NM. Endothelin concentrations in monochorionic twins with severe twin-twin transfusion syndrome. Hum Reprod 1999;14(6):1614-1618.
76. Senat MV, Deprest J, Boulvain M, Paupe A, Winer N, Ville Y. Endoscopic laser surgery versus serial amnioreduction for severe twin to twin transfusion syndrome. N Engl J Med 2004;351(2):136-144.

77. Salomon LJ, Ortqvist L, Aegerter P, et al. Long-term developmental follow-up of infants who participated in a randomized clinical trial of amniocentesis vs laser photocoagulation for the treatment of twin-to-twin transfusion syndrome. Am J Obstet Gynecol 2010;203(5):444.e1-7.

78. Crombleholme TM, Shera D, Lee $H$, et al. A prospective, randomized, multicenter trial of amnioreduction vs selective fetoscopic laser photocoagulation for the treatment of severe twin-twin transfusion syndrome. Am J Obstet Gynecol 2007;197(4):396.e1-9.

79. Yamamoto M, El Murr L, Robyr R, Leleu F, Takahashi Y, Ville Y. Incidence and impact of perioperative complications in 175 fetoscopy guided laser coagulations of chorionic plate anastomoses in fetofetal transfusion syndrome before 26 weeks of gestation. Am J Obstet Gynecol 2005;193(3-Part 2):1110-1116.

80. Ville Y, Hecher K, Gagnon A, Sebire N, Hyett J, Nicolaides K. Endoscopic laser coagulation in the management of severe twin-to-twin transfusion syndrome. Br J Obstet Gynaecol 1998;105(4):446-453.

81. Hecher K, Diehl W, Zikulnig L, Vetter M, Hackeloer BJ. Endoscopic laser coagulation of placental anastomoses in 200 pregnancies with severe mid-trimester twin-to-twin transfusion syndrome. Eur J Obstet Gynecol Reprod Biol 2000;92(1):135-139.

82. Huber A, Diehl W, Bregenzer T, Hackeloer BJ, Hecher K. Stage-related outcome in twin-twin transfusion syndrome treated by fetoscopic laser coagulation. Obstet Gynecol 2006; 108(2):333-337.

83. Morris RK, Selman TJ, Harbidge A, Martin WI, Kilby MD. Fetoscopic laser coagulation for severe twin-to-twin transfusion syndrome: factors influencing perinatal outcome, learning curve of the procedure and lessons for new centers. BJOG 2010;117(11):1350-1357.

84. Quintero RA, Ishii $\mathrm{K}$, Chmait RH, Bornick PW, Allen MH, Kontopoulos EV. Sequential selective laser photocoagulation of communicating vessels in twin-twin transfusion syndrome. J Matern Fetal Neonatal Med 2007;20(10):763-768.

85. Sutcliffe AG, Sebire NJ, Pigott AJ, Taylor B, Edwards PR, Nicolaides $\mathrm{KH}$. Outcome for children born after in utero laser ablation therapy for severe twin-to-twin transfusion syndrome. BJOG 2001;108(12):1246-1250.

86. Banek CS, Hecher K, Hackeloer BJ, Bartmann P. Long-term neurodevelopmental outcome after intrauterine laser treatment for severe twin-twin transfusion syndrome. Am J Obstet Gynecol 2003;188(4):876-880.

87. Graef C, Ellenrieder B, Hecher K, Hackeloer BJ, Huber A, Bartmann P. Long-term neurodevelopmental outcome of 167 children after intrauterine laser treatment for severe twin-twin transfusion syndrome. Am J Obstet Gynecol 2006;194(2):303-308.

88. Lenclen R, Ciarlo G, Paupe A, Bussieres L, Ville Y. Neurodevelopmental outcome at 2 years in children born preterm treated by amnioreduction or fetoscopic laser surgery for twin-to twin transfusion syndrome: comparison with dichorionic twins. Am J Obstet Gynecol 2009;201(3):291.e1-5. 
89. Lopriore E, Ortibus E, Acosta-Rojas R, et al. Risk factors for neurodevelopment impairment in twin-twin transfusion syndrome treated with fetoscopic laser surgery. Obstet Gynecol 2009;113(2-Part 1):361-366.

90. Blickstein I. Estimation of iatrogenic monozygotic twinning rate following assisted reproduction: pitfalls and caveats. Am J Obstet Gynecol 2005;192(2):365-386.

91. Aston KI, Peterson CM, Carrell DT. Monozygotic twinning associated with assisted reproductive technologies: a review. Reproduction 2008;172(4):377-386.

92. Blickstein I. Monochorionicity in perspective. Ultrasound Obstet Gynecol 2006;27(3):235-238.

93. Nikkels PG, Hack KE, van Gemert MJ. Pathology of twin placentas with special attention to monochorionic twin placentas. J Clin Pathol 2008;61(12):1247-1253.

94. Wee LY, Sullivan M, Humphries K, Fisk NM. Longitudinal blood flow in shared (arteriovenous anastomoses) and nonshared cotyledons in monochorionic placentae. Placenta 2007;28(5-6):516-522.

95. Tan TY, Taylor MJ, Wee LY, Vanderheyden T, Wimalasundera R, Fisk NM. Doppler for artery-artery anastomosis and stageindependent survival in twin-twin transfusion. Obstet Gynecol 2004;103(6):1174-1180.

96. Diehl W, Hecher K, Zikulnig L, Vetter M, Hackeloer BJ. Placental vascular anastomoses visualized during fetoscopic laser surgery in severe mid-trimester twin-twin transfusion syndrome. Placenta 2001;22(10):876-881.

97. Mahieu-Caputo D, Dommergues M, Delezoide AL, et al. Twin-to-twin transfusion syndrome: role of the fetal reninangiotensin system. Am J Pathol 2000;156(2):629-636.

98. Fisk NM, Duncombe GJ, Sullivan MH. The basic and clinical science of twin-twin transfusion syndrome. Placenta 2009;30(5):379-390.

99. Galea P, Barigye O, Wee L, Jain V, Sullivan M, Fisk NM. The placenta contributes to activation of the renin angiotensin system in twin-twin transfusion syndrome. Placenta 2008; 29(8):734-742.

100. Rossi CA, D'Addario V. Diagnosis and management of twin to twin transfusion syndrome. Ian Donald School J Ultrasound in Obstet Gynecol 2012 July-Sep;6(3):286-289.

101. De Lia J, Emery MG, Sheafor SA, Jennison TA. Twin transfusion syndrome: successful in utero treatment with digoxin. Int J Gynaecol Obstet 1985 Jun;23(3):197-201.

102. Arabin B, Laurini RN, van Eyck J, Nicolaides KH. Treatment of twin-twin transfusion syndrome by laser and digoxin. Biophysical and angiographic evaluation. Fetal Diagn Ther 1998 May-Jun;13(3):141-146.

103. Bellotti M, Rognoni G, de Gasperi C, Panteghini M, BerlandaN, Ferrazzi E, Buscaglia M. Controlled fetal blood-letting of the recipient twin as a new method for the treatment of severe twin-twin transfusion syndrome: preliminary results. Ultrasound Obstet Gynecol 2001 Dec;18(6):666-668.

104. Moise KJ Jr, Dorman K, Lamvu G, et al. A randomized trial of amnioreduction versus septostomy in the treatment of twin-twin transfusion syndrome. Am J Obstet Gynecol 2005; 193(6):701-707.

105. Umur A, van Gemert MJ, Ross MG. Fetal urine and amniotic fluid in monochorionic twins with twin-twin transfusion syndrome: simulations of therapy. Am J Obstet Gynecol 2001 Oct;185(4):996-1003.
106. Taylor MJ, Shalev E, Tanawattanacharoen S, Jolly M, KumarS, Weiner E, Cox PM, Fisk NM. Ultrasound-guided umbilical cord occlusion using bipolar diathermy for Stage III/IV twintwin transfusion syndrome. Prenat Diagn 2002 Jan;22(1):70-76.

107. Montan S, Jörgensen C, Sjöberg NO. Amniocentesis in treatment of acute polyhydramniosis in twin pregnancies. Acta Obstet Gynecol Scand 1985;64(6):537-539.

108. Bower SJ, Flack NJ, Sepulveda W, Talbert DG, Fisk NM. Uterine artery blood flow response to correction of amniotic fluid volume. Am J Obstet Gynecol 1995 Aug;173(2):502-507.

109. Hecher K, Plath H, Bregenzer T, Hansmann M, Hackelöer BJ. Endoscopic laser surgery versus serial amniocenteses in the treatment of severe twin-twin transfusion syndrome. Am J Obstet Gynecol 1999 Mar;180(3 Pt 1):717-724.

110. Rodeck CH, Weisz B, Peebles DM, Jauniaux E. Hypothesis: the placental 'steal' phenomenon-a possible hazard of amnioreduction. Fetal Diagn Ther 2006;21(3):302-306.

111. Chalouhi GE, Stirnemann JJ, Salomon LJ, Essaoui M, QuibelT, Ville Y. Specific complications of monochorionic twin pregnancies: twintwin transfusion syndrome and twin reversed arterial perfusion sequence. Semin Fetal Neonatal Med 2010;15(6):349-356.

112. Roberts D, Gates S, Kilby M, Neilson JP. Interventions for twin-twin transfusion syndrome: a Cochrane review. Ultrasound Obstet Gynecol 2008;31:701-711.

113. Jackson KM, Mele NL. Twin-to-twin transfusion syndrome: what nurses need to know. Nurs Womens Health 2009 Jun; 13(3):224-232.

114. Johnson JR, Rossi KQ, O'Shaughnessy RW. Amnioreduction versus septostomy in twin-twin transfusion syndrome. Am J Obstet Gynecol 2001;185(5):1044e7

115. Rustico MA, Baietti MG, Coviello D, Orlandi E, Nicolini U. Managing twins discordant for fetal anomaly. Prenat Diagn 2005 Sep;25(9):766-771.

116. Nicolini U, Poblete A. Single intrauterine death in monochorionic twin pregnancies. Ultrasound Obstet Gynecol 1999; 14(5):297-301.

117. Denbow ML, Overton TG, Duncan KR, Cox PM, Fisk NM. High failure rate of umbilical vessel occlusion by ultrasoundguided injection of absolute alcohol or enbucrilate gel. Prenat Diagn 1999;19(6):527-532.

118. Challis D, Gratacos E, Deprest JA. Cord occlusion techniques for selective termination in monochorionic twins. J Perinat Med 1999;27(5):327-338.

119. Deprest JA, Van Ballaer PP, Evrard VA, et al. Experience with fetoscopic cord ligation. Eur J Obstet Gynecol Reprod Biol 1998;81(2):157-164.

120. Hecher K, Hackeloer J, Ville Y. Umbilical cord coagulation by operative microendoscopy at 16 weeks' gestation in an acardiac twin. Ultrasound Obstet Gynecol 1997;10(2):130-132.

121. De Lia JE, Cruikshank DP, Keye WR Jr. Fetoscopic neodymium:YAG laser occlusion of placental vessels in severe twin-twin transfusion syndrome. Obstet Gynecol 1990 Jun;75(6):1046-1053.

122. Quintero RA, Comas C, Bornick PW, Allen MH, Kruger M. Selective $v s$ non-selective laser photocoagulation of placental vessels in twin-to-twin transfusion syndrome. Ultrasound Obstet Gynecol 2000;16(3):230-236.

123. Chmait RH, Assaf SA, Benirschke K. Residual vascular communications in twin-twin transfusion syndrome 
treated with sequential laser surgery: frequency and clinical implications. Placenta 2010;31(7):611-614.

124. Quintero RA, Ishii K, Chmait RH, Bornick PW, Allen MH, Kontopoulos EV. Sequential selective laser photocoagulation of communicating vessels in twin-twin transfusion syndrome. J Matern Fetal Neonatal Med 2007;20(10):763-768.

125. Diemert A, Diehl W, Huber A, Glosemeyer P, Hecher K. Laser therapy of twin-to-twin transfusion syndrome in triplet pregnancies. Ultrasound Obstet Gynecol 2010;35(1):71-74.

126. Bebbington MW, Tiblad E, Huesler-Charles M, Wilson RD, Mann SE, Johnson MP. Outcomes in a cohort of patients with stage I twinto-twin transfusion syndrome. Ultrasound Obstet Gynecol 2010;36(1):48-51.

127. Rossi C, D'Addario V. Survival outcomes of twin-twin transfusion syndrome in stage I: a systematic review of the literature. Am J Perinatol 2012 July 26;1.

128. Meriki N, Smoleniec J, Challis D, Welsh AW. Immediate outcome of twin-twin transfusion syndrome following selective laser photocoagulation of communicating vessels at the NSW fetal therapy center. Aust N Z J Obstet Gynaecol 2010;50(2):112-119.

129. Stamilio DM, Fraser WD, Moore TR. Twin-twin transfusion syndrome: anethics-based and evidence-based argument for clinical research. Am J Obstet Gynecol 2010 Jul;203(1):3-16.

130. Van Mieghem T, Eixarch E, Gucciardo L, Done E, Gonzales I, Van Schoubroeck D, Lewi L, Gratacos E, Deprest J. Outcome prediction in monochorionic diamniotic twin pregnancies with moderately discordant amniotic fluid. Ultrasound Obstet Gynecol 2011 Jan;37(1):15-21.

131. Cruz-Martinez R, Van Mieghem T, Lewi L, Eixarch E, Cobo, T, Martinez JM, Gratacos E. Incidence and clinical implications of early inadvertent septostomy after laser therapy for TwinTwin Transfusion Syndrome. Ultrasound Obstet Gynecol 2011;37(4):458-462.

132. Cavicchioni O, Yamamoto M, Robyr R, Takahashi Y, Ville Y. Intrauterine fetal demise following laser treatment in twinto-twin transfusion syndrome. BJOG 2006;113(5):590-594.

133. Skupski DW, Luks FI, Walker M, et al. Preoperative predictors of death in twin-to-twin transfusion syndrome treated with laser ablation of placental anastomoses.Am J Obstet Gynecol 2010;203(4):388.e1-11.

134. Murakoshi T, Ishii K, Nakata M, et al. Validation of Quintero stage III sub-classification for twin-twin transfusion syndrome based on visibility of donor bladder: characteristic differences in pathophysiology and prognosis. Ultrasound Obstet Gynecol 2008;32(6):813-818.

135. Crombleholme TM, Lim FY, Habli M, et al. Improved recipient survival with maternal nifedipine in twin-twin transfusion syndrome complicated by TTTS cardiomyopathy undergoing selective fetoscopic laser photocoagulation. Am J Obstet Gynecol 2010;203(4):397e1-9.

136. Van Mieghem T, Klaritsch P, Done E, et al. Assessment of fetal cardiac function before and after therapy for twin-totwin transfusion syndrome Am J Obstet Gynecol 2009;200(4): 400.e1-7.

137. Moon-Grady AJ, Rand L, Lemley B, Gosnell K, Hornberger LK, Lee $\mathrm{H}$. Effect of selective fetoscopic laser photocoagulation therapy for twin-twin transfusion syndrome on pulmonary valve pathology in recipient twins. Ultrasound Obstet Gynecol 2011;37(1):27-33.

138. Herberg U, Gross W, Bartmann P, Banek CS, Hecher K, Breuer J. Long-term cardiac follow up of severe twin to twin transfusion syndrome after intrauterine laser coagulation. Heart 2006;92(1):95-100.

139. Li X, Morokuma S, Fukushima K, Otera Y, Yumoto Y, Tsukimori K, Ochiai M, Hara T, Wake N. Prognosis and long-term neurodevelopmental outcome in conservatively treated twin-to-twin transfusion syndrome. BMC Pregnancy Childbirth. 2011 Apr 22;11:32

140. SimonazziG,Segata M,Ghi T, etal. Accurateneurosonographic prediction of brain injury in the surviving fetus after the death of a monochorionic co twin. Ultrasound Obstet Gynecol 2006;27(5):517-521.

141. Righini A, Kustermann A, Parazzini C, Fogliani R, Ceriani F, Triulzi F. Diffusion weighted magnetic resonance imaging of acute hypoxic-ischemic cerebral lesions in the survivor of a monochorionic twin pregnancy: case report. Ultrasound Obstet Gynecol 2007;29(4):453-456.

142. O'Donoghue K, Rutherford MA, Engineer N, Wimalasundera RC, Cowan FM, Fisk NM. Transfusional fetal complications after single intrauterine death in monochorionic multiple pregnancy are reduced but not prevented by vascular occlusion. BJOG 2009;116(6):804-812.

143. Quarello E, Molho M, Ville Y. Incidence, mechanisms, and patterns of fetal cerebral lesions in twin-to-twin transfusion syndrome. J Matern Fetal Neonatal Med 2007;20(8):589-597. 